See discussions, stats, and author profiles for this publication at: https://www.researchgate.net/publication/276127037

\title{
Is There Strength in Numbers?
}

\section{Article $\cdot$ April 2015}

DOI: 10.1163/18763375-00701003

3 authors:

B. Miquel Pellicer

University of Duisburg-Essen

23 PUBLICATIONS 132 CITATIONS

SEE PROFILE

ancesco Cavatort

Laval University

127 PUBLICATIONS 1,245 CITATIONS

SEE PROFILE

Some of the authors of this publication are also working on these related projects:

Project Political parties in the Arab world View project

Project Inequality in South Africa View project 


\title{
Is There Strength in Numbers?
}

\author{
Miquel Pellicer \\ Institute of Middle East Studies, German Institute of Global and Area Studies, \\ Hamburg, Germany \\ Miquel.Pellicer@giga-hamburg.de

\section{Eva Wegner} \\ Institute of Middle East Studies, German Institute of Global and Area Studies, \\ Hamburg, Germany \\ eva.wegner@giga-hamburg.de

\section{Francesco Cavatorta} \\ Department of Political Science, Université Laval, Quebec, Canada \\ francesco.cavatorta@pol.ulaval.ca
}

\begin{abstract}
Studies of the Middle East and North Africa have very often relied on qualitative methodologies to understand and explain the politics of the region. In fact it could be argued that Middle East specialists have tended to shy away purposefully from engaging with quantitative methods because of the perceived 'exceptionalism' of the region in terms of the gathering and reliability of hard data. This article makes the case for increasing engagement with quantitative methodologies in order for studies on the Middle East to better 'speak' to comparative politics more broadly. Far from downplaying the significance and contribution of qualitative methods, this article encourages scholars to integrate them with quantitative methods that have been more recently developed to provide a fuller picture of politics in the region.
\end{abstract}

\section{Keywords}

quantitative methods - qualitative methods - bias - design-based approaches

\footnotetext{
* The authors are grateful to Fiacre Zoungni for compiling the table they use in this article.
} 
Whenever area studies fail to predict a major historical event, such as the fall of the Berlin Wall and the ensuing collapse of the Soviet Union, the 9/11 terrorist attacks, or most recently the Arab Spring, scholars of the respective area are heavily criticised for it. Area scholars, in turn, become defensive and highlight the numerous things they have gotten "right". The summer 2014 issue of Perspectives of Politics is but one example of how such debate has engaged Middle East specialists following the Arab Spring. ${ }^{1}$ Irrespective of the merits and shortcomings of the vast literature on the politics of the Middle East and North Africa, there is no doubt that the Arab Awakening has led to a degree of soulsearching among researchers about what we do and how we go about doing it.

In this article, we argue that the failure to predict historical events is not the right critique to area studies: the goal of social science is not really prediction but analysing and attempting to explain important social and political phenomena. In turn, we argue that area studies tend to overemphasize the exceptionality of "their" region and the need of in-depth knowledge to understand it. Because the perspective is often confined to that particular region, Middle East area studies largely fails to recognize that very similar phenomena might be relevant in other countries and can be addressed by the broader discipline. For example, there is a vast political science literature on political clientelism, a topic to which scholars of Middle East politics could make important contributions but have only exceptionally done so. There is also a large literature on determinants of (regime) responsiveness to voters that is seldom taken up.

One reason for this disconnect between area scholars and other social scientists could be the widespread reluctance among scholars of the Middle East to engage with quantitative methods to map and/or explain political phenomena in the region. There are reasons for the scepticism surrounding quantitative methods, ranging from the validity of data, as Hibou, Meddeb and Hamdi make clear in their study on Tunisia, ${ }^{2}$ to ethical issues of employing statistics that remind many of past colonial practices, to the legitimate concerns about the actual validity of quantitative methods in capturing what are essentially human

1 Marc Morje Howard and Meir Walters, "Explaining the unexpected: political science and the surprises of 1989 and 2011", Perspectives on Politics 12 (2014): 394-408; Eva Bellin, "Response to Howard and Walters", Perspectives on Politics 12 (2014): 409-412; Ellen Lust, "Response to Howard and Walters", Perspectives on Politics 12 (2014): 413-414; Marc Lynch, "Response to Howard and Walters", Perspectives on Politics 12 (2014): 415-416; and Marc Morje Howard and Meir Walters, "Response to Eva Bellin, Ellen Lust and Marc Lynch", Perspectives on Politics 12 (2014): 417-419.

2 Beatrice Hibou, Hamza Meddeb and Mohamed Hamdi, Tunisia after 14January and its social and political economy. Available at http://www.refworld.org/pdfid/515013412.pdf. 
and social interactions. However, borrowing from and speaking to political science research on other world regions through the increasingly common language of quantitative methods would increase the relevance of the field, decrease the pitfalls of overemphasizing Middle East exceptionality, and - in the current context - avoid becoming hostage to studying politics of a region in flux. Currently, the 'language' of quantitative methods enjoys a degree of dominance that, while obviously problematic, should at least be engaged with.

In this article, we make the case for overcoming the methodological disconnect between Middle East area studies and broader political science, suggesting that the relevance of the field can be enhanced through this. A brief look at eight comparative politics journals with a high impact factor during the last five years highlights not only how the vast majority of the articles rely on quantitative methods, but how very few articles deal with the Middle East at a time when interest in the region was considerable (see Table 1 below). For most political science journals, the share of Middle East articles is well below five percent. For instance since 2010 all the articles published in the British Journal of Political Science employed quantitative methods and not one dealt in any way with Middle East politics. This is an extreme case, but it is an indication of the marginalisation of the area in the wider comparative literature.

At the same time, area studies journals publish quantitative studies only rarely. Considering only the number of articles that can be classified as political science the International Journal of Middle East Studies and the Middle East Journal are leading with relatively higher shares of quantitative articles. This however, masks the fact that the IJMES, in particular publishes only a very small number of political science articles, implying that the $100 \%$ of quantitative political science articles in 2010, for instance, only amounts to seven articles using quantitative techniques (see Table 2 below). In addition, many of these articles, at a closer look, employ quantitative methods in a limited way, just to provide descriptive evidence.

The objective here is not to devalue qualitative research, which can be methodologically as sound as quantitative work, ${ }^{3}$ nor to reify quantitative methods, as some in the broader world of political science attempt to do. Rather the goal is to encourage a discussion about 'importing' techniques that other fields of political science employ to further substantiate what we already know and to expand the number and type of the research questions that we can ask. This might not lead to better predictions, but it can contribute to investigate Middle Eastern and North Africa politics outside of the

3 Gary King, Robert Keohane and Sidney Verba, Designing Social Inquiry (Princeton: Princeton University Press, 1994). 
TABLE 1 High Impact Journals in Political Science and Middle East Articles

\begin{tabular}{|c|c|c|c|c|}
\hline Journals & Years & $\begin{array}{l}\text { Total } \\
\text { Articles }\end{array}$ & $\begin{array}{l}\text { Share } \\
\text { Quantitative } \\
\text { Articles (In \%) }\end{array}$ & $\begin{array}{l}\text { Share Quantitative } \\
\text { Middle East Articles } \\
\text { (In \%) }\end{array}$ \\
\hline \multirow{5}{*}{$\begin{array}{l}\text { American Journal } \\
\text { of Political } \\
\text { Science }\end{array}$} & 2010 & $5^{0}$ & 62,0 & 3,2 \\
\hline & 2011 & 59 & 89,8 & 5,7 \\
\hline & 2012 & 57 & 94,7 & 3,7 \\
\hline & 2013 & $6 o$ & 93,3 & 1,8 \\
\hline & 2014 & 62 & 98,4 & 1,6 \\
\hline \multirow{5}{*}{$\begin{array}{l}\text { American Political } \\
\text { Science Review }\end{array}$} & 2010 & 40 & 90,0 & 2,8 \\
\hline & 2011 & 44 & 88,6 & o \\
\hline & 2012 & 42 & 81,0 & 2,9 \\
\hline & 2013 & 44 & 93,2 & 2,4 \\
\hline & 2014 & $5^{0}$ & 90,0 & 2,2 \\
\hline \multirow{5}{*}{$\begin{array}{l}\text { British Journal of } \\
\text { Political Science }\end{array}$} & 2010 & 33 & 100 & o \\
\hline & 2011 & 33 & 100 & o \\
\hline & 2012 & 37 & 94,6 & o \\
\hline & 2013 & 37 & 97,3 & o \\
\hline & 2014 & 36 & 97,2 & o \\
\hline \multirow{5}{*}{$\begin{array}{l}\text { Comparative } \\
\text { Political Studies }\end{array}$} & 2010 & 53 & 100 & 7,5 \\
\hline & 2011 & $5^{6}$ & 100 & 10,7 \\
\hline & 2012 & $5^{2}$ & 100 & 13,5 \\
\hline & 2013 & 59 & 88,1 & 9,6 \\
\hline & 2014 & 70 & 100 & 7,1 \\
\hline \multirow[t]{5}{*}{ Journal of Politics } & 2010 & 83 & 95,2 & 6,3 \\
\hline & 2011 & 88 & 90,9 & o \\
\hline & 2012 & 79 & 92,4 & 4,1 \\
\hline & 2013 & 78 & 94,9 & o \\
\hline & 2014 & 78 & 94,9 & 1,4 \\
\hline \multirow[t]{5}{*}{ Party Politics } & 2010 & 35 & 100 & 8,6 \\
\hline & 2011 & 37 & 100 & 2,7 \\
\hline & 2012 & 45 & 95,6 & o \\
\hline & 2013 & 43 & 100 & 7,0 \\
\hline & 2014 & 74 & 97,3 & 6,9 \\
\hline
\end{tabular}


TABLE 2 Quantitative Methods in AreaJournals

\begin{tabular}{|c|c|c|c|}
\hline Journals & Year & $\begin{array}{l}\text { Polisci } \\
\text { Articles }\end{array}$ & $\begin{array}{l}\text { Share Quantitative } \\
\text { Articles (In \%) }\end{array}$ \\
\hline International Journal of & 2010 & 7 & 100 \\
\hline \multirow[t]{4}{*}{ Middle East Studies } & 2011 & 13 & 69,2 \\
\hline & 2012 & 5 & 20,0 \\
\hline & 2013 & 10 & $5^{0,0}$ \\
\hline & 2014 & 9 & 22,2 \\
\hline \multirow[t]{5}{*}{ Middle East Journal } & 2010 & 19 & 31,6 \\
\hline & 2011 & 17 & $5^{8,8}$ \\
\hline & 2012 & 19 & 73,7 \\
\hline & 2013 & 21 & 47,6 \\
\hline & 2014 & 19 & 26,3 \\
\hline \multirow[t]{5}{*}{ Middle East Policy } & 2010 & 41 & 17,1 \\
\hline & 2011 & 43 & o \\
\hline & 2012 & 45 & 2,2 \\
\hline & 2013 & 46 & 6,5 \\
\hline & 2014 & 35 & 8,6 \\
\hline British Journal of Middle & 2010 & 7 & o \\
\hline \multirow[t]{4}{*}{ Eastern Studies } & 2011 & 17 & 5,9 \\
\hline & 2012 & 17 & o \\
\hline & 2013 & 22 & 9,1 \\
\hline & 2014 & 28 & 17,9 \\
\hline \multirow[t]{5}{*}{ Mediterranean Politics } & 2010 & 14 & 21,4 \\
\hline & 2011 & 19 & 5,3 \\
\hline & 2012 & 21 & 4,8 \\
\hline & 2013 & 20 & o \\
\hline & 2014 & 26 & o \\
\hline
\end{tabular}

'exceptionality' it is often accused of displaying. The usefulness of quantitative methods does not and should not apply to all political phenomena to be analysed or explained, but a more systematic use of quantitative techniques is likely to allow Middle East specialists to connect and 'talk' on a more sustained basis to the broader field of comparative politics.

We discuss the use of quantitative approaches, first, to answer descriptive questions and, second, to address analytical type of questions. We illustrate our arguments using examples from recent quantitative work on the MENA. 
Descriptive statements provide answer to "what" types of questions. These types of statements are a key pillar of scientific enquiry, and are provided by both quantitative and qualitative approaches. A first order question regarding the 2011 wave of protests in the Arab world is what type of individuals participated in those protests (where they primarily young, old, with high or low education?). Ideally one would count each and every participant of protests and ask about their age, education and a plethora of other attributes. However, in this case (as in most others) this is not feasible, and so both quantitative and qualitative researchers, explicitly or implicitly, need to rely on a sample to make descriptive statements. This implies that descriptive statements, both qualitative and quantitative, are typically not exact.

An advantage of quantitative approaches is that they make use of welldeveloped statistical theory to make explicit how good descriptive statements are likely to be. We can thus know if our descriptive statements are likely to be biased (i.e. systematically incorrect) and how precise or uncertain we can expect these statements to be. This depends on how and how much data is collected. Biased descriptive statements can result if the sample collected is not representative of the population. Small samples of related people are likely to provide imprecise estimates. The key point is that these issues are theoretically well understood, so that sampling designs in quantitative approaches are typically now made purposefully.

We believe this can be particularly useful in the context of political science research in the MENA. In particular, researchers collecting their own evidence, as almost all qualitative analysts are, can hardly afford to obtain a random sample of their population of interest. This could lead on occasion to biased descriptive statements. We consider two potential types of bias, bias coming form the researcher and bias coming from informants. We illustrate how quantitative approaches can help address these biases using MENA quantitative work as examples.

\section{Bias of the Researcher}

There are various ways in which bias in the collection of data can originate in the researcher. First, in order to collect data cheaply, the researcher may rely on existing contacts and these contacts are likely not to be representative of the population. Second, despite all their efforts to be objective, researchers, can hardly completely avoid suffering from behavioural biases such as "motivated reasoning", whereby information is filtered depending on how closely it matches with existing beliefs. 
These issues might be particularly problematic when studying political actors in the MENA through western lenses. In particular, these biases are likely to be important when researchers have an affinity towards certain actors rather than others. In the case of Western researchers, it seems plausible that they feel less affinity towards Islamist actors as opposed to, say, secularist actors that presumably are closer to the researcher's values. This would imply that their contacts come primarily from the latter type of actor so that their role could be overestimated. Similarly, information on the support of Islamist actors might be discounted or demeaned. This might occur when one over-emphasises for instance information suggesting that it is just the uneducated and ignorant that support Islamist parties or that people support the Islamist because of patronage or vote buying. Of course the opposite can also be true. Researchers might get too close to the object of study and tend to rely on contacts that have an in-built interest in presenting a specific view (the bias of informants is dealt with in the next section). Thus the problem is not simply about the potential overlap of values with some local actors (and therefore a conflict in values with others), but it is also about the proximity to the actors or phenomenon one is studying or attempting to explain.

Quantitative approaches can help reduce these biases. Quantitative analyses often use administrative data or surveys designed with the aim of being representative. In both cases, data collection is separated from the analysis thus reducing the potential bias of descriptive statements.

A very good example of the usefulness of quantitative evidence is the work of Beissinger et al. precisely on the profile of protesters in the Arab Uprisings. ${ }^{4}$ This article draws on representative surveys in Tunisia and Egypt, with very rich information, not only on socioeconomic characteristics, but also attitudes and, crucially (self-reported) participation in the "Arab Spring" protests. Their samples are of around 1000 respondents in each country. This type of data is unique in its ability to deliver a priori unbiased information on the characteristics of protesters (assuming respondents give truthful answers to the questionnaire, of course). Their results confirm some expectations, such as that protesters had higher education and higher access to the internet than average. However, some results are more surprising and, arguably, difficult to obtain in any other way. They find for example that the majority of respondents claims to have protested driven by economic grievances rather than political ones.

4 Mark Beissinger, Amaney Jamal, and Kevin Mazur, "Who Participates in 'Democratic' Revolutions? A Comparison of the Egyptian and Tunisian Revolutions" paper presented at the Annual Convention of the American Political Science Association, August $29^{\text {th }}$ - September $2^{\text {nd }}, 2012$. 
This is an important question where commentators have disagreed, with some authors emphasizing economic grievances and others political ones. ${ }^{5}$ Quantitative evidence such as that in Beissinger et al., based on a sample representative of the population, represents thus an important contribution to the debate.

A second example of the usefulness of quantitative techniques is work on support for Islamist parties, including our own work in Morocco. ${ }^{6}$ We use two sources of data: matched census-electoral data at the district level, and survey data at the individual level. We provide descriptive evidence on the profile of citizens supporting the Islamist party in Morocco focusing, among others, on education. Using the two data sources, we find a strong positive relation between education and vote for the Islamist party (PJD). This suggests that clientelism is not the dominant motive of support for the PJD. Similar results are obtained by El-Said and Rauch for Jordan. ${ }^{7}$ These authors conduct an individual survey of active members of the Islamic Action Front (IAF), the Jordanian Islamist party. They find that, relative to the Jordanian average, IAF members display considerably higher education levels.

The key point of these examples is that the values and contacts of authors (we believe) matter little in the process of obtaining the results and thus concerns about bias should be less acute. This does not imply that results will always be different when using quantitative evidence. As the two examples show, some findings are in line with conventional wisdom (protesters in the Arab revolts were more educated than average), some less so (Islamist supporters appear to be rather highly educated). The point is rather that it brings attention to the issue of bias potential in the anecdotal and politicised nature of qualitative evidence. In addition, these types of quantitative results have an advantage in terms of comparability and, by extension, the elimination of Arab exceptionalism from scholarly work. While there is a widespread reluctance, as mentioned in the introduction, to embrace quantitative methods

5 Andrea Ansani, and Vittorio Daniele, "About a Revolution. The Economic Motivations of the Arab Spring." International Journal of Development and Conflict 2, no. 3 (2012): 1-24; Oliver Schlumberger, and Torsten Matzke, "Path toward Democracy? The Role of Economic Development." Swiss Political Science Review 18, no. 1 (2012): 105-9 ; Charles Tripp ; "The Politics of Resistance and the Arab Uprisings," In The New Middle East: protest and revolution in the Arab World, ed. Fawaz A. Gerges (New York: Cambridge University Press, 2014), 135-154.

6 Miquel Pellicer and Eva Wegner, "Socio-Economic Voter Profile and Motives for Islamist Support in Morocco." Party Politics 20, no. 1 (2014): 116-33.

7 Hamed EL-Said and James Rauch, "Education, Political Participation, and Islamist Parties: The Case of Jordan's Islamic Action Front." Middle East Journal, (forthcoming 2015). 
among many area studies scholars, such findings can be very useful in 'speaking' to a larger comparative politics audience already familiar with quantitative techniques and therefore able to incorporate studies about the MENA in their work.

\section{Bias of the Informant}

A second potential source of bias is the bias of informants. Researchers often rely on sources for information that have their own agendas and incentives, and these might lead them to provide biased information. This concern has been, arguably, particularly important in MENA political science research, for two reasons. First is because there has been a strong focus on studying elites and regimes regarding highly contentious topics such as authoritarian resilience. Second, because of the authoritarian nature of these regimes, control of information is particularly valuable.

In this context, quantitative descriptive evidence can be valuable. As an example, we consider our own research on the experience of local governance of the PJD. ${ }^{8}$ We selected three localities where the PJD had been governing for several years. We conducted qualitative work such as interviews with the mayor and with members of opposition groups. In all towns, predictably, mayors communicated stories of success, citing an array of successful projects they had undertaken. Members of the opposition, also predictably, communicated the opposite story, of incompetence and, in some instances, corruption and clientelism.

During our fieldwork, we tried to obtain information on the evolution of budget income and expenditures in the different towns. This was a difficult task, as some officials were unwilling to share this information. Ultimately, however, the investment paid off. The budgets showed a very different evolution of capital expenditures in the different towns. Capital expenditures had skyrocketed in two of the towns (Oued Zem and Ksar el Kbir) while it stayed relatively constant in the other one (Temara). Despite a similar discourse on the part of the mayor and opposition, our quantitative evidence (among others) suggested a more successful tenure in Oued Zem and Ksar el Kbir than in Temara. And indeed, in the following elections, the PJD dramatically increased its vote share in the two former towns, but not in the latter.

This short example illustrates how descriptive quantitative work can shed light on issues that other methods of investigation would not be able to clarify because of the bias of informants upon which researchers will have to rely.

8 Miquel Pellicer and Eva Wegner, "The Moroccan Party of Justice and Development in Local Politics." Middle East Journal, (forthcoming 2015). 
Descriptive evidence is key to uncover useful facts and patterns. However, most of the relevant research questions in political science are analytical; i.e. about causal relations. The nexus between relevance and causation might be over-emphasised in the discipline, but it is nevertheless important to engage with it. Remaining with our example about protests in the Arab Uprisings, it has been widely argued that one of the root causes of the protests were the massive educational expansion in the region since the 196os. This expansion would have led to heightened aspirations which, unfulfilled would have generated the grievances underlying the protests. ${ }^{9}$ Descriptive evidence on the profile of protesters (whether they were particularly highly educated or not) helps making the hypothesis plausible or implausible, but does not directly address it. The analytical question of relevance for this hypothesis is: did demonstrators protest because they were educated? i.e. was it their very education that led them to protest? In order to provide credible evidence on this issue, therefore, the issue of causality needs to be carefully considered. We argue that quantitative approaches have undergone a veritable revolution that has provided tools and approaches to generate evidence on these questions in a credible way. Moreover, scholars with extensive area expertise are particularly well suited to take advantage of these new opportunities.

\section{The Credibility Crisis of Quantitative Analysis}

Until recently, the most common way of addressing causal questions in quantitative social sciences was to collect observational data and run regressions of the outcome variables of interest (the "dependent" variable) on a set of explanatory variables (the "independent" variables), trying to control for as many factors as possible. Regression coefficients provide good measures of association between the outcome and explanatory variables and the addition of control variables help keeping constant observed characteristics.

However, interpreting regression results from observational data as causal is problematic: individuals (or countries, or whatever the unit of analysis) tend to differ in many ways, many of which are unobservable and thus impossible to

9 Filipe R Campante and Davin Chor, "Why Was the Arab World Poised for Revolution? Schooling, Economic Opportunities, and the Arab Spring," The Journal of Economic Perspectives 26, no 2 (2012): 167-87. Jack A. Goldstone, "Understanding the Revolutions of 2011: Weakness and Resilience in Middle Eastern Autocracies," Foreign Affairs 90 (2011): 8. Howard Sanborn and Clayton L. Thyne, "Learning Democracy: Education and the Fall of Authoritarian Regimes" British Journal of Political Science 44, no 4 (2014), 773-797. 
control for; regressing an outcome on an explanatory variable conflates the effect of the explanatory variable with unobservable differences between units. For instance, when estimating the effect of education on some outcome by comparing outcomes of people with more and less education, the comparison conflates the effect of education with all the differences that exist between people with high and low education (family background, ability, etc.) This problem is neither new nor obscure, and is typically stated as "correlation is not causation".

Because regression coefficients with observational data deliver a jumble of effects, they are often unstable: adding or subtracting control variables to a regression can substantially change coefficients of interest. This has led to a severe critique of quantitative analytical approaches, considering them subject to manipulation by the researcher and, ultimately, almost meaningless. In a recent publication, Angrist and Pischke ${ }^{10}$ refer to an old criticism towards this type of quantitative approaches, where Leamer wrote a piece provocatively entitled "Let's Take the Con Out of Econometrics", arguing that "hardly anyone takes data analysis seriously. Or perhaps more accurately, hardly anyone takes anyone else's data analysis seriously".11

\section{Design-Based Approaches}

Angrist and Pischke argue that the spread of "design based" approaches in recent years/ decades has begun to restore credibility to quantitative social sciences. Design based approaches stress the importance of pre-analysis design, as opposed to post-analysis control, to estimate causal effects. The clearest examples of design-based study are randomized control trials, which are borrowed from the medical sciences, where the explanatory variable of interest (the "treatment" - like giving an aspirin) is given randomly to some units and not to others. The randomization ensures that treated units are a priori identical to non-treated ones, so that comparison of outcomes between treated and non-treated units delivers the causal effect of the treatment. Control variables are not necessary and, if used, ought to have essentially no impact on coefficients of interest, making results stable and causal inferences, credible.

In political science, three types of "design based" approaches have become common. These are survey experiments, field experiments, and natural experiments.

10 Joshua Angrist and Jörn-Steffen Pischke, "The Credibility Revolution in Empirical Economics: How Better Research Design Is Taking the Con out of Econometrics," (Cambridge, MA: National Bureau of Economic Research, 2010).

11 Edward E. Leamer, "Let's Take the Con out of Econometrics," The American Economic Review 73, no 1 (1983): 31-43. 
Few studies using these approaches have been conducted in the MENA and we argue that this avenue of research is particularly fruitful for MENA political science research.

Survey and field experiments are fully designed by the researcher. Survey experiments are normal surveys, where a survey item is given to a random set of respondents (the "treated group"), but not to others (the "control group"). This item can be some information, additional questions, etc. Outcome questions are then asked and comparisons of outcomes between the treatment and control groups deliver the causal effect of the treatment given. Survey experiments are now routinely used in political science to study drivers of attitudes as varied as attitudes towards redistribution, immigration or corruption, and drivers of voting behaviour more generally.

Two of the few survey experiments to date on politics in the MENA are Benstead et al. and Marinov. ${ }^{12}$ In Benstead et al., the authors are interested in potential bias of voters against or towards females and explicitly religious candidates in Tunisia. This is an important question that speaks, among others, to potential barriers to gender equity in the region. It is however a question difficult to answer by asking people directly, because there may be social norms that prevent people from displaying a bias if they have one. It is also difficult to answer the question by comparing, say, votes obtained by females in elections vs. those obtained by males. The reason is that females may stand in peculiar types of district or, most important, females standing as candidates might have very peculiar characteristics. Differences in votes between males and females will conflate voter gender biases with differences between female and male candidates in district and personal characteristics. Benstead et al. thus tackle the question using a survey experiment. They provide pictures with candidates and ask respondents to rate these candidates. Half of the sample receives a female picture whereas the other half receives a male one (similarly with religious-looking vs. non-religious looking candidates). Besides the gender of the candidate, everything else is kept as constant as possible. Using this methodology, Benstead et al. find little overall gender bias, although each candidate profile is preferred by specific type of people (for instance, the female secular candidate ranks better among those that want to redress the gender imbalance). Another interesting study conducted through survey experiment is the

12 Lindsay Benstead, Amaney Jamal, and Ellen Lust, "Is it Gender, Religiosity or Both? A Role Congruity Theory of Candidate Electability in Transitional Tunisia," Perspective on Politics, (forthcoming 2015); Nikolay Marinov, "Voter Attitudes When Democracy Promotion Turns Partisan: Evidence From a Survey-Experiment in Lebanon," Democratization 20 (2013): 1297-1321. 
one by Marinov on how voters react when foreign actors meddle in fragile democratic politics by supporting a specific party to the detriment of all the others. Marinov looked specifically at the case of Lebanon and demonstrated that attempting to 'guide' democratic processes from abroad negatively impacts educated and politically sophisticated voters most.

Field experiments provide more realistic findings than survey experiments because they involve "real" treatments (rather than the "artificial" treatments embedded in surveys), and "real" behaviour (rather than opinion outcomes, as survey experiments do). For instance, Wantchekon, in a famous early field experiment in political science, studies the effect of clientelistic vs. programmatic campaigning on voter behaviour in Benin's elections. ${ }^{13}$ Treatment and outcomes are real: one party did modify randomly its campaign in different villages, and the outcome measured is actual voting for the party in subsequent elections. This is a relatively unique and remarkable example of a field experiment, but many others have been conducted that are easier to implement. Researchers have looked, for instance, at the effect of voter education campaigns or at the effect of providing information about corruption of local politicians on accountability. These field experiments typically require teaming up with NGOs and argue for randomizing one of their programs in order to assess their effectiveness.

Natural experiments are different than survey and field experiments in that the researcher does not design the treatment. Instead, the researcher uses a real existing policy or institution that generates treatment and control groups in a random or quasi-random way. An example of this is our own work on electoral rules in Morocco. ${ }^{14}$ We were interested in understanding the role of these rules on voting behaviour. Comparing, say, countries with different electoral rules is likely not to yield the causal effect of electoral rules because countries with different electoral rules are likely to differ in many respects difficult to control for. Morocco's election law provides us with a "natural experiment" that can be used to estimate these effects. In Morocco's local elections, the electoral system depends on population size: towns smaller than a given population threshold (25,000 in 2003 and 35,000 in 2009) use a majoritarian system, while those with population higher than this vote using proportional representation.

13 Leonard Wantchekon, "Clientelism and Voting Behavior: Evidence from a Field Experiment in Benin," World Politics 55, no. 3 (2003): 399-422.

14 Miquel Pellicer and Eva Wegner, "Electoral Rules and Clientelistic Parties: A Regression Discontinuity Approach," Quarterly Journal of Political Science 8, no. 4 (2013): 339-71. Miquel Pellicer and Eva Wegner, "The Mechanical and Psychological Effects of Legal Thresholds" Electoral Studies 33 (2014): 258-66. 
Towns close to the corresponding population threshold are likely to be very similar on average, but because of the institutional setting, those just above the threshold have a different electoral rule. Thus, one can consider a priori that being at the right or at the left side of the population threshold is random, and so is therefore the electoral rule treatment. This is why this design can be considered a "natural experiment", where "nature" (here the Moroccan government) provides us with an experimental design.

These design-based approaches have the important advantage of providing credible causal effects but also have their limitations and problems. In particular, survey, field and natural experiments all have their advantages and disadvantages, and there are important trade-offs to assess when considering embarking in any of them.

Survey and field experiments have some specific limitations. First, they may suffer from low external validity; i.e. the extent to which results from the study can be generalized to other settings. This is particularly problematic for survey experiments, which generate treatments in a somewhat artificial manner. Field experiments fare better in this regard although they sometimes remain somewhat artificial (ex. people often know they are part of a field experiment) and particularly small-scale (small successful interventions might not remain successful when scaled up). Second, survey experiments and, particularly, field experiments can be extremely demanding and costly. Both require the collection of primary data with a sufficient sample size to make sensible inferences. In addition, for field experiments, the unit of analysis often needs to be the community in order to obtain real world outcomes and so information on a substantial amount of communities needs to be collected, a costly endeavour. Field experiments are particularly demanding for their need to partner with NGOs or other organizations, as interests between researchers and the other organizations may diverge at some point. Third, there are some questions of interest that simply cannot be addressed via survey or field experiments. For instance, one can hardly study the effect of education with such methods. Finally, survey and field experiments require the consideration of ethical issues. In these types of experiment, researchers are purposefully providing a treatment to respondents that respondents otherwise would not obtain and there maybe ethical issues involved that require clearing.

Natural experiments avoid most of these pitfalls, but have their own ones. Most importantly, questions of study are severely limited by available policy and institutional settings. One cannot simply choose to study the effect of this on that. Natural experiments need to be found and only then the analysis can proceed. This distracts research attention away from thinking about interesting questions towards looking for settings that allows one to answer some 
questions, which may or may not be interesting. In addition, natural experiments, particularly in developing countries, have the problem of the frequent divergence between law and practice: natural experiments based on laws or policies that look good "on paper" might not have been implemented well or not at all on the ground.

\section{Looking Ahead: Opportunities for Design-Based Approaches in the MENA}

However, even with all these limitations, it is probably fair to say that design based approaches have revolutionized empirical economics and political science. The ability to deliver a credible estimate of a causal effect, to provide a number that we can feel quite certain reflects the effect of a treatment of an outcome (for a particular population) is invaluable from a scientific point of view.

There is ample scope to apply such approaches to research about MENA politics. This would allow for testing whether causal mechanisms uncovered in other regions of the world apply to the MENA. To the extent that there are MENA peculiarities, they could be used to push the frontiers of disciplinary research by means of common, robust and well-understood methods. Moreover, MENA regimes being relative interventionist socially and politically has led to an abundance of rules that can be exploited as natural experiments, such as the electoral rules in Morocco.

Moreover, we believe MENA "area" scholars are in a unique position to exploit this opportunity. The technical requirements to undertake such design-based approaches are, while not trivial, also not too demanding. ${ }^{15}$ Most importantly, the successful implementation of such approaches requires in depth knowledge of the context in which the studies take place. Treatments in survey experiments need to be designed in a way that is well understood and that achieves the intended results on respondents. Field experiments require partnerships with local actors, where trust between the parties is key for the success of the endeavour. Natural experiments can only be found with in depth knowledge of the specific institutional setting and can only be exploited successfully with detailed knowledge of how policies and laws were implemented.

15 See, for example, the comprehensive treatments on field experiments and natural experiments in Duflo, Esther, Rachel Glennerster, and Michael Kremer. "Using randomization in development economics research: A toolkit." Handbook of development economics 4 (2007): 3895-3962, and Dunning, Thad. Natural experiments in the social sciences: a design-based approach. Cambridge University Press, 2012, respectively. 


\section{$4 \quad$ Concluding Remarks}

Employing new quantitative techniques in the study of Middle East politics should not go to the detriment of qualitative ones, which have greatly contributed to the knowledge we have of the politics of the region. Without in-depth ethnographic studies or without detailed analyses of discourses and actors based on participant observations, Middle East studies would be much poorer. This article suggests that such qualitative techniques can be integrated with quantitative ones in order to expand the range of research questions we can ask and, crucially, to end of idea of regional exceptionality so many of us decry. The opportunity to take up a 'language' through which the broader field of political science can be engaged and interrogated should be seized. 